Article

\title{
Bone Marrow Aspirate Concentrate Is More Effective Than Hyaluronic Acid and Autologous Conditioned Serum in the Treatment of Knee Osteoarthritis: A Retrospective Study of 505 Consecutive Patients
}

\author{
Mohsen Hussein ${ }^{1,2,3, *(\mathbb{D})}$, Carola F. van Eck ${ }^{4}$ (D) and Nevenka Kregar Velikonja ${ }^{1,5}$ (D) \\ 1 Faculty of Health Sciences, University of Novo Mesto, 8000 Novo Mesto, Slovenia; \\ nevenka.kregar-velikonja@uni-nm.si \\ 2 Artros Center for Orthopaedic Surgery and Sports Medicine, 1000 Ljubljana, Slovenia \\ 3 Institute for Celular Regenerative Medicine, 1000 Ljubljana, Slovenia \\ 4 Orthopaedic Engineering \& Sports Medicine Laboratory, Department of Orthopaedic Surgery, \\ University of Pittsburgh, Pittsburgh, PA 15203, USA; vaneckc@upmc.edu \\ 5 Educell, Cell Therapy Company, Prevale 9, 1236 Trzin, Slovenia \\ * Correspondence: Mhussein@artros.si; Tel.: +386-40-300-124
}

check for

updates

Citation: Hussein, M.; van Eck, C.F.; Kregar Velikonja, N. Bone Marrow Aspirate Concentrate Is More Effective Than Hyaluronic Acid and Autologous Conditioned Serum in the Treatment of Knee Osteoarthritis: A Retrospective Study of 505 Consecutive Patients. Appl. Sci. 2021, 11, 2932. https:// doi.org/app11072932

Academic Editor: Hanatsu Nagano

Received: 27 February 2021

Accepted: 22 March 2021

Published: 25 March 2021

Publisher's Note: MDPI stays neutral with regard to jurisdictional claims in published maps and institutional affiliations.

Copyright: (c) 2021 by the authors. Licensee MDPI, Basel, Switzerland. This article is an open access article distributed under the terms and conditions of the Creative Commons Attribution (CC BY) license (https:/ / creativecommons.org/licenses/by/ $4.0 /)$.
Featured Application: This study shows differences in the efficacy of hyaluronic acid (HA), autologous conditioned serum (ACS) and bone marrow aspirate concentrate (BMAC) intra-articular injections to improve pain and symptoms of knee OA up to one year after treatment. BMAC treatment gives best results at $\mathbf{1 2}$ months and is effective also in the patients with more advanced knee osteoarthritis (OA). The study results will be beneficial in making evidence-based orthopaedic decisions on the method of $\mathrm{OA}$ treatment based on the levels of cartilage wear, as no clear guidelines have been provided regarding this issue.

Abstract: The aim of this study was to evaluate and compare the effectiveness of three different intra-articular injective treatments: hyaluronic acid (HA), autologous conditioned serum (ACS) and bone marrow aspirate concentrate (BMAC) for the treatment of knee osteoarthritis (OA). A Level III retrospective comparative clinical study was performed on 505 consecutive patients treated with HA $(n=171)$, ACS $(n=222)$ or BMAC $(n=112)$ for knee OA. The mean patient age was $52 \pm 13$ years; $54.5 \%$ were males. Collected data included patient demographics, symptoms, visual analogue scale (VAS), Western Ontario and McMaster Universities Osteoarthritis Index (WOMAC) and radiographic classification of osteoarthritis grade using plain radiographs and advanced imaging. Clinical outcome was assessed at 3 and 12 months post treatment. Significant improvement in VAS and WOMAC was seen for all three treatments at the 3-month follow-up. At 12 months, VAS was improved in all three treatment groups, yet only BMAC sustained the improved WOMAC even in patients with more severe degenerative changes. This study shows that BMAC is more effective than HA and ACS in the treatment of symptomatic knee OA, especially in the patients with more severe degenerative changes.

Keywords: osteoarthritis; knee; hyaluronic acid; autologous conditioned serum; bone marrow aspirate concentrate; clinical outcome

\section{Introduction}

Osteoarthritis (OA) is a multifactorial joint disease that can lead to pain, dysfunction and a decreased quality of life [1]. It is the most common joint disorder, affecting millions of people worldwide [2,3]; knee OA is one of the main reasons for physical disability [4]. Unfortunately, there is no disease-modifying medical intervention to prevent or cure this disease. Therefore, the mainstay of treatment is focused on symptom relief. Many 
patients revert to total joint arthroplasty for definitive management of their OA; however, this is not always a viable option, depending on patient age, surgical risk and medical comorbidities [5]. A widely used conservative treatment measure is intra-articular injection of corticosteroids [2]. Over the past two decades, the use of naturally derived preparations, called orthobiologics, for various orthopedic conditions has become increasingly popular, including for the management of knee OA. This includes the improvement or regeneration of different musculoskeletal tissues by means of biomaterials (e.g., hyaluronic acid (HA)), stem cells and growth factors (e.g., platelet-rich plasma (PRP)) [6,7].

However, neither intra-articular corticosteroids nor HA and PRP injectables have been recommended for the management of knee OA in the guidelines published by the American Academy of Orthopaedic Surgeons (AAOS) [5,8]. Cell products were not considered in these guidelines.

Basic science studies have found that orthobiologics-unlike corticosteroids-have the potential to improve the condition of the joint rather than just the symptom by modulating inflammation and facilitating cartilage healing [9-14].

Some of the most frequently used types of orthobiologics include hyaluronic acid (HA) as an important component of the intercellular matrix [15-17], platelet rich plasma (PRP) $[11,12,14,18,19]$ and autologous conditioned serum (ACS) $[20,21]$, as well as cell preparations from stem cell rich sources [22].

Cell products include cultivated mesenchymal stem cells (MSCs) [23], adipose derived mesenchymal stem cells (AD MSC) [24], adipose derived stromal vascular fraction (AD-SVF) [25] and bone marrow aspirate concentrate (BMAC) [26]. Different cell treatments show a significant improvement in functional outcome and in tissue regeneration, resulting in improved radiological outcome parameters $[22,27,28]$. Moreover, MSCs offer the potential for cartilage regeneration owing to their effective immunomodulatory properties and anti-inflammatory abilities [29]. There is growing evidence that PRP has anti-inflammatory characteristics [30], whereas ACS has even superior immunomodulating capacity $[20,21]$. PRP treatment has been shown to decrease pain, but no significant disease-altering properties have been consistently reported [5]. PRP augmentation has also been shown as beneficial to accelerate and prolong the therapeutic effect of microfracturation for the treatment of OA [31]. Hyaluronic acid injections are thought to work by two separate mechanisms of action [15]. First, the viscosupplementation lubricates damaged cartilage surfaces, allowing for less friction and inflammation and therefore less joint pain and swelling. Secondly, HA acts as a nutrient for chondrocytes that may still be able to heal when given a more favorable, nutrient-rich environment [15]. Clinical trials have demonstrated its effectiveness for the management of knee OA and superiority to corticosteroid injections when the duration of symptom relief is of concern 16,17].

The aim of this study was to evaluate the clinical effectiveness of three intra-articular injections (HA, ACS and BMAC) in the treatment of symptomatic knee OA. There are a few studies comparing various kinds of orthobiologics [21,32-34]. However, to our knowledge, currently there are no studies simultaneously comparing the outcomes of HA, ACS and BMAC intra-articular injection treatments for the management of knee OA. It was hypothesized that the three treatments would result in symptom improvement, and that BMAC would have the greatest effect on pain and dysfunction, followed by ACS and HA.

\section{Materials and Methods}

A retrospective clinical study was conducted between 2009 and 2018 on patients with OA of the knee, graded according to Kellgren-Lawrence (KL) [35,36], treated either with HA, ACS or BMAC via intra-articular injection. The treatment method was selected according to the patient's preferences regarding the procedure's invasiveness and cost. In clinical practice, it is generally more likely to start with less invasive and also less expensive treatment in patients with a lower degree of degenerative changes. All three treatments were performed by the first author. From a total of 644 potentially eligible cases, treated with HA, ACS or BMAC during the defined period, 505 met the inclusion criteria: 171 in 
the HA group, 222 in the ACS group and 112 in the BMAC group (Figure 1, Table 1). The study protocol was approved by the National Medical Ethics Committee (approval number 0120-286/2018-4).

\begin{tabular}{|c|c|c|}
\hline \multicolumn{3}{|c|}{ Patients with OA in knee joint } \\
\hline $\begin{array}{l}\text { HA cohort: } \\
\text { Period: 2009-2018 }\end{array}$ & $\begin{array}{l}\text { ACS cohort: } \\
\text { Period: 2011-2018 }\end{array}$ & $\begin{array}{l}\text { BMAC cohort } \\
\text { Period: } 2015-2018\end{array}$ \\
\hline $\begin{array}{l}\text { Knee joints treated and } \\
\text { assessed for eligibility: } \\
n=228\end{array}$ & $\begin{array}{l}\text { Knee joints treated and } \\
\text { assessed for eligibility: } \\
n=284\end{array}$ & $\begin{array}{l}\text { Knee joints treated and } \\
\text { assessed for eligibility: } \\
n=132\end{array}$ \\
\hline \begin{tabular}{|l} 
Excluded: \\
48 cases with chondral \\
injury grade 4 or \\
undefined chondral injury \\
grade; \\
9 cases not meeting age \\
inclusion criteria
\end{tabular} & \begin{tabular}{|l} 
Excluded: \\
57 cases with chondral \\
injury grade 4 or \\
undefined chondral injury \\
grade; \\
5 cases not meeting age \\
inclusion criteria
\end{tabular} & \begin{tabular}{|l} 
Excluded: \\
16 patients with chondral \\
injury grade 4 or \\
undefined chondral injury \\
grade; \\
4 cases not meeting age \\
inclusion criteria
\end{tabular} \\
\hline Eligible: $n=171$ cases & Eligible: $n=222$ cases & Eligible: $n=112$ cases \\
\hline 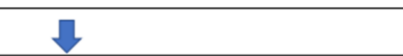 & $\nabla$ & $\checkmark$ \\
\hline 3-months follow-up: $n=145$ & 3-months follow-up: $n=201$ & 3-months follow-up: $n=98$ \\
\hline$V$ & $\checkmark$ & 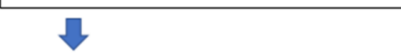 \\
\hline 1-year follow-up: $n=30$ & 1-year follow-up: $n=50$ & 1-year follow-up: $n=25$ \\
\hline
\end{tabular}

Figure 1. Flowchart of the study showing the number of eligible patients, number of included patients and number of included knees, reasons for exclusion and follow-up percentage at 3 and 12 months. HA = hyaluronic acid; ACS = autologous conditioned serum; BMAC = bone marrow aspirate concentrate.

Table 1. Demographic data of the included cases.

\begin{tabular}{cccccc}
\hline & Age & \multicolumn{2}{c}{ Sex } & \multicolumn{2}{c}{ Laterality } \\
\hline $\begin{array}{c}\text { Treatment } \\
\text { Group }\end{array}$ & Mean \pm SD & $\begin{array}{c}\text { Male } \\
\text { N (\%) }\end{array}$ & $\begin{array}{c}\text { Female } \\
\text { N (\%) }\end{array}$ & $\begin{array}{c}\text { Left } \\
\text { N (\%) }\end{array}$ & $\begin{array}{c}\text { Right } \\
\text { N (\%) }\end{array}$ \\
\hline HA & $51 \pm 15$ & $88(52)$ & $83(48)$ & $76(44)$ & $95(56)$ \\
ACS & $51 \pm 13$ & $121(57)$ & $101(43)$ & $109(49)$ & $113(51)$ \\
BMAC & $52 \pm 10$ & $66(59)$ & $46(41)$ & $52(46)$ & $60(54)$ \\
Total & $52 \pm 13$ & $287(54)$ & $247(46)$ & $251(47)$ & $283(53)$ \\
Baseline & & & & & \\
differences & $p=0.689$ & & & & \\
between \\
groups
\end{tabular}

SD = standard deviation; $\mathrm{N}=$ number of cases; $\mathrm{HA}$ = hyaluronic acid $; \mathrm{ACS}$ = autologous conditioned plasma; $\mathrm{BMAC}=$ bone marrow aspirate concentrate.

\subsection{Inclusion and Exclusion Criteria}

The inclusion criteria were as follows: (1) KL classification of knee OA grades I-III, diagnosed on radiograph and MRI imaging; (2) pain in the knee joint (VAS $\geq 1$ ); and (3) the patient age between 18 and 80 years. The exclusion criteria were as follows: (1) grade IV degenerative changes as determined by the KL classification, (2) if the grade of arthritis could not be determined from the medical records, (3) inflammatory arthropathies such as rheumatoid arthritis and connective tissue diseases, (4) the presence of another source of significant pain or dysfunction affecting the ability to isolate symptoms of the affected knee when evaluating the effectiveness of the treatment and (5) if the patients had already received a similar type of injection or surgical intervention within 12 months prior to treatment. 


\subsection{Treatment Procedures}

In the HA group, patients were treated with an intra-articular injection of 500-730 kDA sodium hyaluronate (Suplasyn, Mylan, Zurich, Switzerland). Patients received three injections of $20 \mathrm{mg}$ of this substance, in $2 \mathrm{~mL}$ of volume, at weekly intervals as suggested by He et al. [17].

Patients treated with ACS (Orthokin, Orthogen, Dusseldorf, Germany) had $60 \mathrm{~mL}$ of their own blood drawn from the antecubital fossa by an experienced nurse in sterile conditions. The collecting system was then used to spin down and process the autologous blood into ACS. It was then frozen and stored under $-20^{\circ} \mathrm{C}$, according to manufacturer's instructions and quality standards employed by the institution conducting the study. Patients received a total of six intra-articular injections every 3-4 days for 3 weeks as suggested by manufacturer.

The BMAC group underwent bone marrow aspiration by the first author using a commercially available procedure kit (Regen Extracell, RegenLab SA, Lousanne, Switzerland). Patients were placed in supine position, the harvest site was prepared and draped in the standard fashion and a total of $32 \mathrm{~mL}$ of bone marrow was aspirated from the anterior iliac crest under general anesthesia. Using the aforementioned kit, aspirated bone marrow was concentrated to $8 \mathrm{~mL} /$ application. A single intra-articular injection of $8 \mathrm{~mL}$ of BMAC was performed on the same day as bone marrow aspiration.

All patients also received instructions for post-treatment rehabilitation including exercises, daily and sports activities as recommended by AAOS guidelines for management of OA.

\subsection{Outcome Measures}

Prior to intervention, demographic data (age, sex, laterality), plain radiographs and magnetic resonance imaging (MRI) studies scans were collected for all cases. The grade of OA was documented using the KL classification [35,36]. In addition, all patients assessed their pain and symptom severity using the Visual Analogue Scale (VAS) and Western Ontario and McMaster Universities Osteoarthritis Index (WOMAC). The VAS score was used for general subjective estimation of pain, whereas the WOMAC is more specific for pain associated with orthopaedic problems. After the treatment, patients were followed for a minimum of 1 year. None of the patients had serious adverse events (e.g., infection, allergic reaction, the need to have the knee drained or surgical irrigation and debridement). After treatment, two patients treated with BMAC reported severe pain up to 7 days post treatment. The VAS and WOMAC were repeated at 3 and 12 months following intervention. Some patients were lost to follow-up which resulted in 145 HA cases (84\%), 201 ACS cases $(90.5 \%)$ and 98 BMAC cases (87.5\%) at 3 months; and 30 HA cases (17.5\%), 50 ACS cases $(22.5 \%)$ and 25 BMAC cases $(22.3 \%)$ at 12 months (Figure 1). The demographic data of the included subjects is displayed in Table 1 . The average patient age was 52 years (SD 13 years); $54 \%$ of cases were males and $46 \%$ females. Knee OA involved the right knee in $53 \%$ of cases and the left knee in $47 \%$. There were no significant demographic differences among the treatment groups.

\subsection{Statistical Analysis}

All results were checked for normality, and subsequently reported as mean and standard deviation (SD). Statistical analysis was performed using SPSS (version 25, IBM Corporation Armonk, New York, NY, USA). Continuous data are expressed as means with standard deviation. Test of normality (Shapiro Wilks) was used for ANOVA in residuals to verify the adherence to normality assumptions. One-way analysis of variance (ANOVA) testing and Bonferroni post-hoc test were used to determine the differences between the treatment groups. The Spearman's rank test was used to determine the association of the OA grade and patient age with VAS and WOMAC scores. A paired samples t-test was used for within group analysis of treatment efficacy. Statistical significance was set at $p<0.05$. 


\section{Results}

\subsection{Baseline Characteristics of Treatment Groups}

OA grade, VAS and WOMAC score for each of the three treatment groups prior to intervention are displayed in Table 2. At baseline, there was a difference in OA severity and symptoms; the highest OA grade, VAS and WOMAC scores were observed in the BMAC group $(2.6 \pm 0.5,5.2 \pm 1.3$ and $7.9 \pm 2.2$, respectively), and the lowest in the HA group (2.1 $\pm 0.7,3.9 \pm 1.6$ and $5.8 \pm 1.9$, respectively) $(p<0.001)$. Due to significant differences in baseline values of VAS and WOMAC scores, score changes were used for comparison of treatment efficacy among the treatment groups.

Table 2. Preintervention difference in grade of osteoarthritis, VAS and WOMAC scores between treatment groups.

\begin{tabular}{|c|c|c|c|c|}
\hline Treatment Group & HA & ACS & BMAC & Significance \\
\hline & Mean (SD) & Mean (SD) & Mean (SD) & $p$ Value \\
\hline OA grade & $2.13 \pm 0.74$ & $2.35 \pm 0.73$ & $2.62 \pm 0.54$ & $\begin{array}{c}+p=0.007, \ddagger p=0.003 \\
\quad \text { 市 } p<0.001\end{array}$ \\
\hline VAS & $3.94 \pm 1.55$ & $4.51 \pm 1.32$ & $5.13 \pm 1.28$ & $\begin{array}{c}+p<0.001, \ddagger p<0.001 \\
+\frac{\top}{+} p<0.001\end{array}$ \\
\hline WOMAC & $5.82 \pm 1.92$ & $6.52 \pm 1.96$ & $7.92 \pm 2.24$ & $\begin{array}{c}+p=0.002, \ddagger p<0.001, \\
\quad+p<0.001\end{array}$ \\
\hline
\end{tabular}

$\mathrm{HA}=$ hyaluronic acid; ACS = autologous conditioned serum; BMAC = bone marrow aspirate concentrate; $\mathrm{SD}=$ standard deviation; $\mathrm{OA}=$ osteoarthritis; VAS = Visual Analogue Scale; WOMAC = Western Ontario and McMaster Universities Osteoarthritis Index; statistical significance of the difference between + HA and ACS, $\ddagger$ ACS and BMAC, 市 HA and BMAC.

The Pearson correlation coefficient between the grade of OA and the VAS and WOMAC score prior to treatment shows a moderate positive relationship between the grade of OA and the VAS score for the total study cohort, as well as the three individual treatment groups (Table 3). For the WOMAC score, this was also true with the exception of the BMAC group, in which there was no significant correlation between the OA grade and the WOMAC score; only three patients from the BMAC group had OA grade I.

Table 3. Correlation between grade of OA and preintervention VAS and WOMAC score, respectively.

\begin{tabular}{ccccc}
\hline & \multicolumn{2}{c}{$\begin{array}{c}\text { Correlation between OA Grade } \\
\text { \& VAS }\end{array}$} & \multicolumn{2}{c}{$\begin{array}{c}\text { Correlation between OA Grade } \\
\text { \& WOMAC }\end{array}$} \\
\hline Treatment Group & $\begin{array}{c}\text { Spearman Correlation } \\
\text { Coefficient (r) }\end{array}$ & $p$ Value & $\begin{array}{c}\text { Spearman Correlation } \\
\text { Coefficient (r) }\end{array}$ & $p$ Value \\
\hline HA & $0.53+$ & $<0.001$ & $0.67+$ & $<0.001$ \\
ACS & $0.35+$ & $<0.001$ & $0.46+$ & $<0.001$ \\
BMAC & $0.39+$ & $<0.001$ & -0.26 & 0.788 \\
Total & $0.47+$ & $<0.001$ & $0.48+$ & $<0.001$ \\
\hline
\end{tabular}

$\mathrm{OA}=$ osteoarthritis; VAS = Visual Analogue Scale; WOMAC = Western Ontario and McMaster Universities Osteoarthritis Index; HA = hyaluronic acid; ACS = autologous conditioned plasma; BMAC = bone marrow aspirate concentrate; + statistically significant correlation.

\subsection{Follow-Up Outcomes}

The changes in VAS and WOMAC scores in all three treatment groups at the 3- and 12-month follow-ups are presented in Figure 2. Significant improvement was observed in all groups at 3 months in both scores; however, at 12 months, a significant improvement as compared to baseline values persisted in the VAS score in the ACS group, and in both the VAS and WOMAC scores in the BMAC group (Tables 4 and 5). Pain was significantly more persistent in older patients as older patient age was associated with a higher VAS $(\mathrm{r}=-0.21, p<0.001)$ and WOMAC score $(\mathrm{r}=-0.13, p=0.008)$ at the 3-month follow-up. 


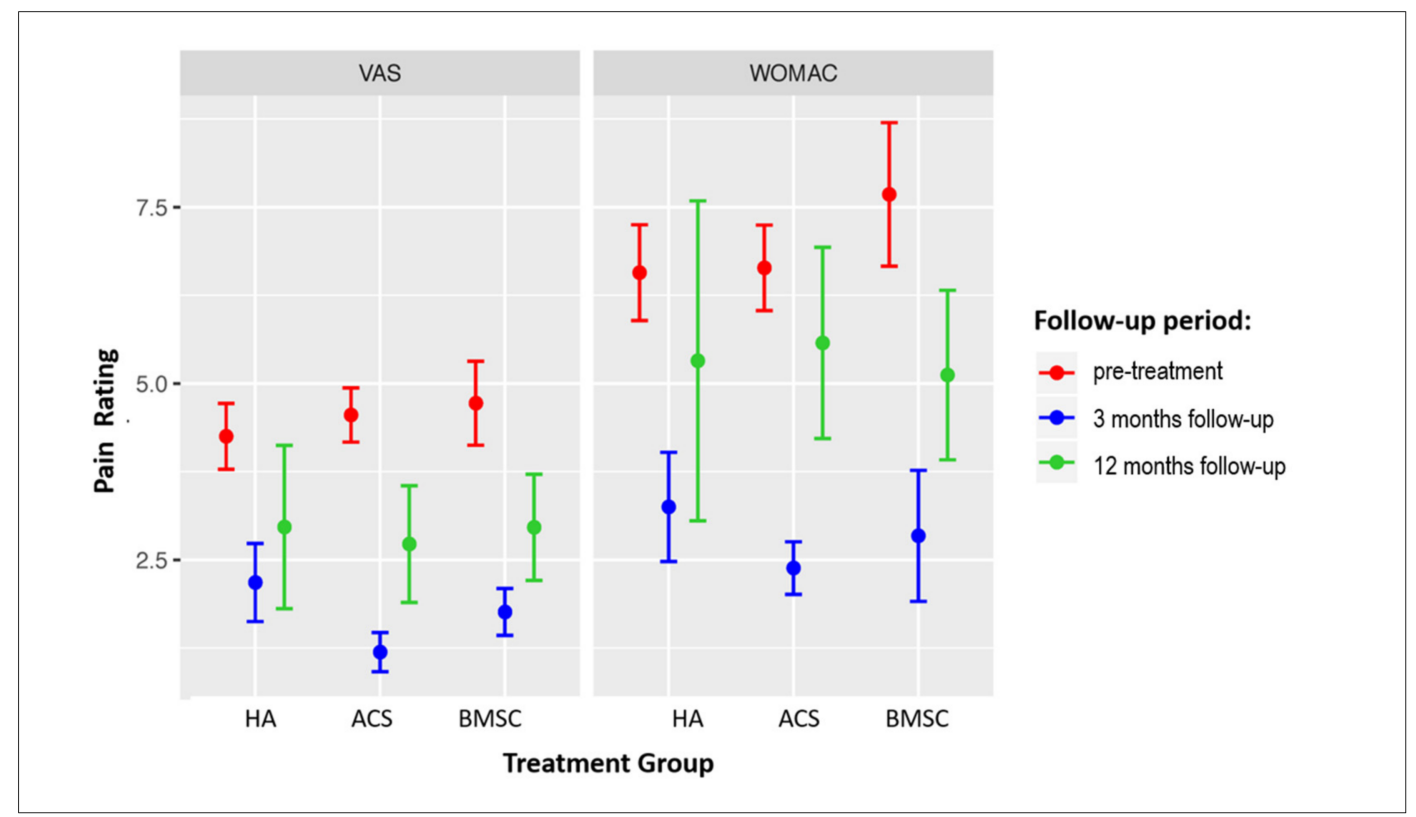

Figure 2. Forest plot showing VAS and WOMAC scores in patients treated with three different treatment modalities. Mean score values \pm SEM are presented. Sample sizes of individual groups are presented in Figure 1. OA = osteoarthritis; VAS = Visual Analogue Scale; WOMAC = Western Ontario and McMaster Universities Osteoarthritis Index. HA = hyaluronic acid; ACS = autologous conditioned serum; BMAC = bone marrow aspirate concentrate.

Table 4. Change in VAS score 3 and 12 months after the treatment with HA, ACS and BMAC.

\begin{tabular}{ccccc}
\hline & Pretreatment & 3-Month Follow-Up & 1-Year Follow-Up & $\begin{array}{c}\text { Significance of Change in VAS } \\
\text { Score after Treatment }\end{array}$ \\
\hline $\begin{array}{c}\text { Treatment } \\
\text { Group }\end{array}$ & $\begin{array}{c}\text { Mean } \pm \text { SD } \\
\mathbf{( N )}\end{array}$ & $\begin{array}{c}\text { Mean } \pm \text { SD } \\
\mathbf{( N )}\end{array}$ & $\begin{array}{c}\text { Mean } \pm \text { SD } \\
\mathbf{( N )}\end{array}$ & $p$ Value \\
\hline HA & $4.3 \pm 1.2(171)$ & $2.2 \pm 1.4(145)$ & $2.9 \pm 3.0(30)$ & $\dagger p<0.001, \ddagger p=0.017, p=0.164$ \\
ACS & $4.5 \pm 1.3(222)$ & $1.9 \pm 1.0(201)$ & $2.7 \pm 2.8(50)$ & $\dagger p<0.001, \ddagger p<0.001, p<0.001$ \\
BMAC & $4.7 \pm 1.5(112)$ & $1.8 \pm 0.8(98)$ & $3.0 \pm 0.8(25)$ & $+p<0.001, \ddagger p=0.003, p=0.003$ \\
Total & $4.5 \pm 1.3(505)$ & $1.6 \pm 1.15(444)$ & $2.9 \pm 2.7(105)$ & $+p<0.001, \ddagger p<0.001, p<0.001$ \\
\hline
\end{tabular}

VAS = Visual Analogue Scale; HA = hyaluronic acid; ACS = autologous conditioned serum; BMAC = bone marrow aspirate concentrate; statistically significant improvement between +0 and 3 months, $\ddagger 0-12$ months, $3-12$ months.

Table 5. Change in WOMAC score 3 and 12 months after the treatment with HA, ACS and BMAC.

\begin{tabular}{ccccc}
\hline & Pretreatment & 3-Month Follow-Up & 1-Year Follow-Up & $\begin{array}{c}\text { Significance of Change in VAS } \\
\text { Score after Treatment }\end{array}$ \\
\hline $\begin{array}{c}\text { Treatment } \\
\text { Group }\end{array}$ & $\begin{array}{c}\text { Mean } \pm \text { SD } \\
\mathbf{( N )}\end{array}$ & $\begin{array}{c}\text { Mean } \pm \text { SD } \\
\mathbf{( N )}\end{array}$ & $\begin{array}{c}\text { Mean } \pm \text { SD } \\
\mathbf{( N )}\end{array}$ & $p$ Value \\
\hline HA & $6.25 \pm 1.78(171)$ & $3.24 \pm 2.01(145)$ & $5.32 \pm 6.0(30)$ & $+p<0.001, \pm p=0.278, \pm p=0.055$ \\
ACS & $6.64 \pm 2.08(222)$ & $2.38 \pm 1.27(201)$ & $5.57 \pm 4.65(50)$ & $+p<0.001, \pm p=0.143, \pm p<0.001$ \\
BMAC & $7.68 \pm 2.54(112)$ & $2.84 \pm 2.32(98)$ & $5.12 \pm 3.00(25)$ & $\dagger p<0.001, \ddagger p=0.005, + \pm p=0.003$ \\
Total & $6.86 \pm 2.16(505)$ & $2.74 \pm 1.82(444)$ & $5.39 \pm 4.70(105)$ & $+p<0.001, \ddagger p=0.003, \pm p<0.001$ \\
\hline
\end{tabular}

WOMAC = Western Ontario and McMaster Universities Osteoarthritis Index; HA = hyaluronic acid; ACS = autologous conditioned serum; $\mathrm{BMAC}=$ bone marrow aspirate concentrate; statistically significant improvement between +0 and 3 months, $\ddagger 0-12$ months, $3-12$ months.

\subsection{Association of Pain Score Changes with OA Grade}

The association of pain score changes with OA grade in different treatment groups was analysed. Table 6 shows the correlation between the OA grade and the changes in the VAS and WOMAC scores at 3 and 12 months in response to treatment. Negative $r$ values mean that better improvement is achieved in patients with a higher OA grade, and positive 
values mean that a better improvement is achieved in patients with lower OA grades. In general, better short-term (at 3 months) results are observed in patients with higher grades of $\mathrm{OA}$, and better long-term results are observed in patients with lower grades of OA. The patients from the three treatment groups with OA grade I and II had improvement in pain and function at both 3 and 12 months after treatment; the short-term improvement achieved in patients with grade III changes was decreased at 12 months (Figure 3); negative values of the presented score changes mean decrease of pain.

Table 6. Correlation between grade of OA and change in VAS and WOMAC score over the follow-up period.

\begin{tabular}{|c|c|c|c|c|}
\hline \multirow[b]{2}{*}{ Treatment Group } & \multicolumn{2}{|c|}{$\begin{array}{l}\text { Spearman Correlation Coefficient } \\
\text { between OA Grade \& VAS Change } \\
\text { r ( } p \text { Value })\end{array}$} & \multicolumn{2}{|c|}{$\begin{array}{l}\text { Spearman Correlation Coefficient } \\
\text { between OA Grade \& WOMAC Change } \\
\mathrm{r}(p \text { Value })\end{array}$} \\
\hline & $\begin{array}{l}\text { Pretreatment to } \\
3 \mathrm{mo} \mathrm{f} / \mathrm{u}\end{array}$ & $\begin{array}{l}\text { Pretreatment to } \\
\qquad 12 \mathrm{mo} \mathrm{f} / \mathrm{u}\end{array}$ & $\begin{array}{l}\text { Pretreatment to } \\
3 \mathrm{mo} \mathrm{f} / \mathrm{u}\end{array}$ & $\begin{array}{l}\text { Pretreatment to } \\
12 \mathrm{mo} \mathrm{f} / \mathrm{u}\end{array}$ \\
\hline HA & $-0.20(0.015)+$ & $0.50(0.005)+$ & $-0.42(<0.001)+$ & $0.68(<0.001)+$ \\
\hline ACS & $-0.36(<0.001)+$ & $0.26(0.069)$ & $-0.44(<0.001)+$ & $0.17(0.056)$ \\
\hline BMAC & $-0.27(0.006)+$ & $-0.06(0.78)$ & $0.06(0.592)$ & $0.16(0.459)$ \\
\hline Total & $-0.33(<0.001)+$ & $0.28(0.004)+$ & $-0.39(0.001)+$ & $0.34(<0.001) \dagger$ \\
\hline
\end{tabular}

OA = osteoarthritis; VAS = Visual Analogue Scale; WOMAC = Western Ontario and McMaster Universities Osteoarthritis Index; $\mathrm{HA}=$ hyaluronic acid $\mathrm{ACS}=$ autologous conditioned serum; $\mathrm{BMAC}=$ bone marrow aspirate concentrate $; \mathrm{mo}=$ month; $\mathrm{f} / \mathrm{u}=\mathrm{follow}$-up; $\dagger$ statistically significant correlation.

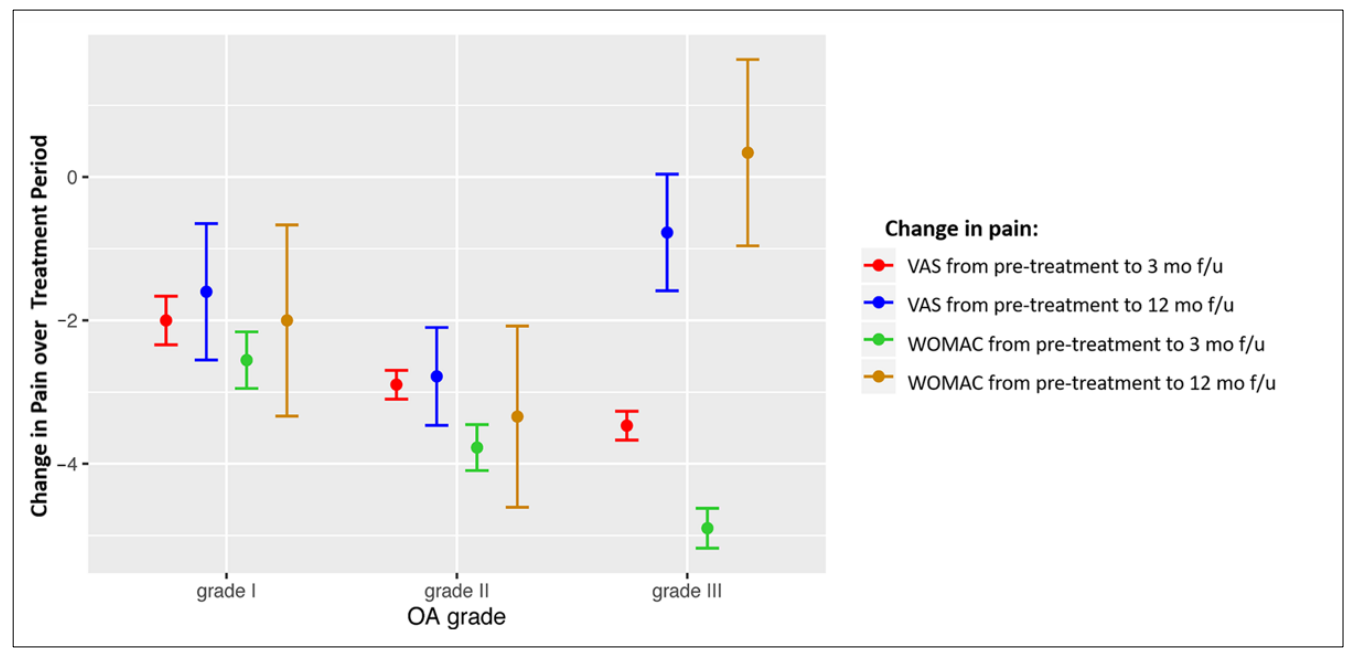

Figure 3. Forest plot showing VAS and WOMAC score changes in patients with different OA grades for the overall study cohort. Mean values of score change \pm SEM are presented. OA = osteoarthritis; VAS = Visual Analogue Scale; WOMAC = Western Ontario and McMaster Universities Osteoarthritis Index; $\mathrm{mo}=$ months; $\mathrm{f} / \mathrm{u}=$ follow-up.

Figure 4 shows the changes in VAS and WOMAC scores according to the grade of OA in different treatment groups to illustrate associations given in Table 6. The improvement in pain scores at 3 months decreased significantly at 12 months in all three treatment groups. In the HA group, an increase in the VAS and WOMAC scores at 12 months was observed in patients with grade III OA. In patients with grade III OA treated with ACS, pain scores were not significantly different from baseline values. In the BMAC group, a significant decrease in pain scores was sustained at the 12-month follow-up, even in cases with OA grade III (Figure 4). 


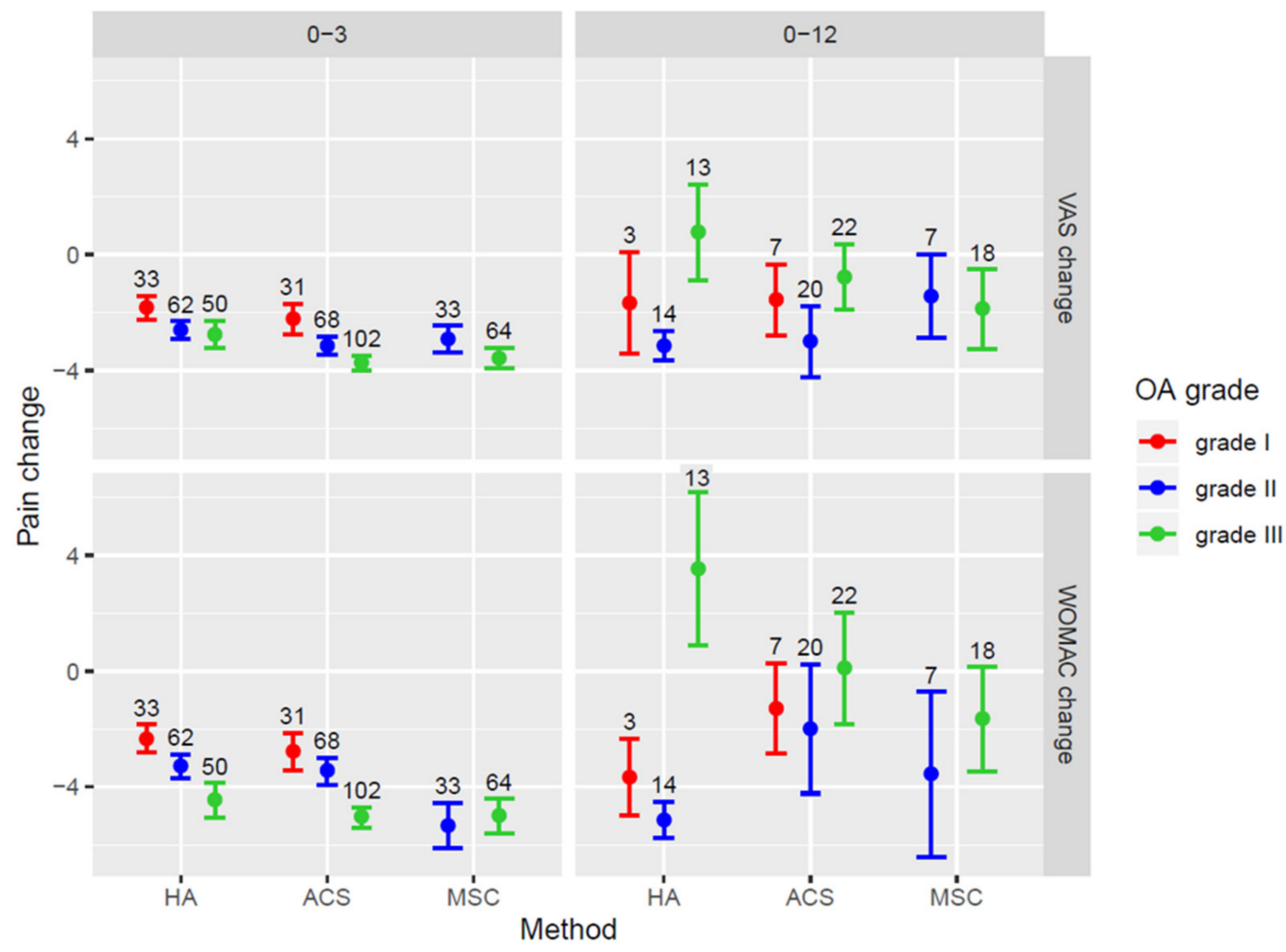

Figure 4. Forest plot showing VAS and WOMAC score changes in patients with different OA grades for the patient groups treated with separate treatment methods. Mean values of score change \pm SEM are presented. OA = osteoarthritis; VAS = Visual Analogue Scale; WOMAC = Western Ontario and McMaster Universities Osteoarthritis Index. HA = hyaluronic acid; ACS = autologous conditioned serum; BMAC = bone marrow aspirate concentrate.

\section{Discussion}

The aim of this study was to compare the efficacy of HA, ACS and BMAC in the treatment of symptomatic knee OA. The most important findings were that all three treatment methods resulted in an improvement in the VAS and WOMAC scores at the 3-month follow-up. However, at 12 months, the WOMAC scores remained improved only in patients treated with BMAC. In addition, BMAC was most effective in the patients with more severe (KL grade III) degenerative changes.

The lack of sustained effect of HA treatment is consistent with previous reports in the literature. A meta-analysis of 76 trials comparing various types of HA injections to other treatment options for OA concluded that HA had a positive effect on pain associated with weightbearing function, and the positive effect was most pronounced 5 to 13 weeks post injection [37]. The current AAOS guidelines cannot recommend HA for symptomatic knee OA; although some meta-analyses have shown improvement in the WOMAC score, the number of points with which patients assessed their improvement did not meet the minimal clinically important improvement thresholds [8]. In this study, the treatment with ACS showed an improvement in the VAS but not in the WOMAC score at 1 year after treatment, which is somewhat different from previous studies. Yang et al., looking at the efficacy of ACS in the treatment of symptomatic knee OA in a double-blind placebocontrolled trial, found an improvement in the Knee Injury and Osteoarthritis Outcome Score (KOOS) and in the symptom and sport subscores [38]. Although there appeared to be a trend towards improvement in other three subscores as compared to placebo, this did not reach statistical significance. Similar to the present study, they did not find a significant difference in the WOMAC score at 12-month post treatment [38]. Baltzer et al. compared ACS to HA and normal saline [20] and found that all three treatment groups showed symptom reduction. In line with the present study, the symptom reduction was better with ACS and HA, but they found no difference in improvement between HA and normal saline. 
They noted, however, that HA injection had a significantly higher complication rate than ACS and normal saline [20].

BMAC has been found superior to HA and ASC in the present study, showing an effect of treatment even at a 12-month follow-up; it was most effective in patients with higher grade knee OA. A potential explanation may be that the pluripotent stem cells present in BMAC are able to promote chondrogenesis and cartilage regeneration $[23,26,32,34,39]$. In addition, these cells can secrete certain growth factors resulting in an anti-inflammatory and immunomodulating effect on the knee, which may slow down or even prevent OA progression [40]. Consistent with this, a meta-analysis by Jeyaraman et al. showed a statistically significant improvement after MSC (derived either from bone marrow or adipose tissue) transplantation in all functional outcome measures such as VAS for pain, WOMAC, Lysholm, Knee Injury and Osteoarthritis Outcome Score (KOOS) and radiological outcome parameters such as Whole-Organ Magnetic Resonance Imaging Score (WORMS) at different time intervals with their corresponding controls. The study showed an improvement in OA symptoms with a bone marrow derived cultured stem cell injection; the VAS score was found improved even at 2 years post treatment. However, the authors pointed out that there were no studies comparing the effect of BMAC and culture expanded bone marrow derived mesenchymal stem cells (BM-MSCs) [31].

Similar to the present study, other studies have indicated that the effectiveness of OA treatment is directly related to the severity of the disease [26,27]. Centeno et al. looked at BMAC with and without an adipose graft for knee OA and found that both were equally effective, but the magnitude of symptom improvement was dependent on the grade of degenerative changes also in their study [26]. Kim et al. looked at the effect of BMAC with adipose tissue injection on OA symptoms [27]. They found an improvement in the International Knee Documentation Committee (IKDC), Short Form 36 (SF-36), Lysholm and KOOS scores. Although all patients had symptom improvement with treatment, the effect was much less in the patients with grade IV KL changes, when compared to the patients with grade I-III changes. The same authors further reported mid-term follow-up results of OA patients treated with BMAC [41]. They found that the VAS scores five years after treatment were significantly lower than the preoperative scores; however, the improvement in VAS scores was significantly greater in patients with KL Grade I or II than in those with KL Grade III or IV.

Lastly, the present study has shown an effect of age on the outcome of treatment, which is seen in some [42] but not in other of the aforementioned studies [5,43]. This can be partly explained by older patients generally having more advanced degenerative changes, as well as by the reduced number of stem cells available and their proliferative capacity with increased age [44-46].

\section{Study Limitations and Strengths}

As a retrospective study, the present study does have some limitations. Treatment was not randomized, patients and providers were not blinded to the treatment provided and no placebo or saline group was used. The number of cases included in each treatment group was different. Initially, a relatively large number of patients were present in each group; however, a significant number of patients were lost to follow-up between 3 and 12 months post treatment. There were baseline differences between the groups in the grade of $\mathrm{OA}$, VAS and WOMAC. This is largely due to the retrospective nature of the study as in these patients presenting with milder degenerative changes in the clinical setting, it is more likely to start with the least invasive and also the least expensive treatment $[15,47]$. Lastly, the efficacy of the treatment could be affected by other factors such as at the frequency/number of treatment visits. The BMAC group had only one single visit, whereas three visits were needed in the HA group, and six were needed in the ACS group. The number of visits and time spent with the treating physician might have an additional placebo effect on the perceived efficacy of treatment, although this has not been confirmed by previous research [48]. 
The strengths of the study are that this is the first study to report comparison of three different orthobiologic treatments. All patients were treated by the same surgeon with the same technique and underwent the same rehabilitation protocol, therefore minimizing variability of treatment procedure among involved individuals.

This study highlights the potential of orthobiologics in the treatment of knee OA. In the future, prospective trials with large patient numbers and longer follow-ups are needed to further elucidate the duration of their efficacy. For this, patients should be additionally followed with MRI imaging tests to get objective data as well as patient subjective assessments of treatment outcomes.

\section{Conclusions}

This study shows that HA, ACS and BMAC intra-articular injections improve pain and symptoms of knee OA up to three months after treatment. However, BMAC is more effective than HA and ACS as it sustains symptom improvement for at least 12 months post treatment. In addition, BMAC is the most effective in the patients with more advanced knee OA.

Author Contributions: Conceptualization, M.H., N.K.V. and C.F.v.E.; methodology, N.K.V. and C.F.v.E.; validation, M.H., N.K.V. and C.F.v.E.; formal analysis, M.H.; clinical investigation, M.H.; resources, M.H. and N.K.V.; data curation, M.H. and N.K.V.; writing-original draft preparation, M.H. and N.K.V.; writing-review and editing, C.F.v.E.; visualization, N.K.V. and C.F.v.E.; supervision, M.H.; project administration, N.K.V.; funding acquisition, N.K.V. All authors have read and agreed to the published version of the manuscript.

Funding: This research was funded by Public Scholarship, Development, Disability and Maintenance Fund of the Republic of Slovenia, grant number 11081-13/2018-7.

Institutional Review Board Statement: The study was conducted according to the guidelines of the Declaration of Helsinki, and reviewed and approved by the National Medical Ethics Committee (0120-286/2018-4).

Informed Consent Statement: Patient consent was waived due to retrospective nature of the study. Data was anonymized before analysis. Study protocol was approved by the National Medical Ethics Committee (0120-286/2018-4).

Data Availability Statement: The data presented in this study are available on request from the corresponding author.

Acknowledgments: The authors would like to thank Anja Zakrajšek for technical support in data collection.

Conflicts of Interest: The authors declare no conflict of interest and have no financial disclosures with regards to the research presented in this manuscript. N.K.V. is partially employed at Educell, cell therapy company [Trzin, Slovenia]. Educell was not involved in the design or execution of this study, nor were any of the treatments used in this study a product of Educell. The funders had no role in the design of the study; in the collection, analyses, or interpretation of data; in the writing of the manuscript; or in the decision to publish the results.

\section{Abbreviations}

AAOS American Academy of Orthopaedic Surgeons

ACS autologous conditioned serum

BMAC bone marrow aspirate concentrate

HA hyaluronic acid

MSCs mesenchymal stem cells

OA osteoarthritis

PRP platelet rich plasma

SEM standard error of the mean

VAS Visual Analogue Scale

WOMAC Western Ontario and McMaster Universities Osteoarthritis Index 


\section{References}

1. Hesper, T.; Bittersohl, B.; Schleich, C.; Hosalkar, H.; Krauspe, R.; Krekel, P.; Zilkens, C. Automatic cartilage segmentation for delayed gadolinium-enhanced magnetic resonance imaging of hip joint cartilage: A feasibility study. Cartilage 2020, 11 , 32-37. [CrossRef]

2. Conrozier, T.; Monfort, J.; Chevalier, X.; Raman, R.; Richette, P.; Diraçoglù, D.; Bard, H.; Baron, D.; Jerosch, J.; Migliore, A.; et al. EUROVISCO recommendations for optimizing the clinical results of viscosupplementation in osteoarthritis. Cartilage 2020, 11, 47-59. [CrossRef]

3. Woolf, A.D.; Pfleger, B. Burden of major musculoskeletal conditions. Bull. World Health Organ. 2003, 81, 646-656. [CrossRef]

4. Henrotin, Y.; Chevalier, X.; Raman, R.; Richette, P.; Montfort, J.; Jerosch, J.; Baron, D.; Bard, H.; Carrillon, Y.; Migliore, A.; et al. EUROVISCO guidelines for the design and conduct of clinical trials assessing the disease-modifying effect of knee viscosupplementation. Cartilage 2020, 11, 60-70. [CrossRef]

5. Cotter, E.J.; Frank, R.M.; Mandelbaum, B. Management of osteoarthritis—Biological approaches: Current concepts. J. ISAKOS 2020, 5, 27-31. [CrossRef]

6. Sherman, B.J.; Chahla, J.; Glowney, J.; Frank, R.M. The role of orthobiologics in the management of osteoarthritis and focal cartilage defects. Orthopedics 2019, 42, 66-73. [CrossRef]

7. Pereira, H.; Sousa, D.A.; Cunha, A.; Andrade, R.; Espregueira-Mendes, J.; Oliveira, J.M.; Reis, R.L. Hyaluronic acid. Adv. Exp. Med. Biol. 2018, 1059, 137-153. [CrossRef]

8. Jevsevar, D.S.; Brown, G.A.; Jones, D.L.; Matzkin, E.G.; Manner, P.A.; Mooar, P.; Gross, L. The American Academy of Orthopaedic Surgeons evidence-based guideline on: Treatment of osteoarthritis of the knee. JBJS 2013, 95, 1885-1886. [CrossRef] [PubMed]

9. Kingery, M.T.; Manjunath, A.K.; Anil, U.; Strauss, E.J. Bone marrow mesenchymal stem cell therapy and related bone marrowderived orthobiologic therapeutics. Curr. Rev. Musculoskelet. Med. 2019, 12, 451-459. [CrossRef] [PubMed]

10. Centeno, C.J.; Pastoriza, S.M. Past, current and future interventional orthobiologics techniques and how they relate to regenerative rehabilitation: A clinical commentary. Int. J. Sports Phys. Ther. 2020, 15, 301-325. [CrossRef]

11. Osterman, C.; McCarthy, M.B.R.; Cote, M.P.; Beitzel, K.; Bradley, J.; Polkowski, G.; Mazzocca, A.D. Platelet-rich plasma increases anti-inflammatory markers in a human coculture model for osteoarthritis. Am. J. Sports Med. 2015, 43, 1474-1484. [CrossRef]

12. Everts, P.; Onishi, K.; Jayaram, P.; Lana, J.F.; Mautner, K. Platelet-rich plasma: New performance understandings and therapeutic considerations in 2020. Int. J. Mol. Sci. 2020, 21, 7794. [CrossRef] [PubMed]

13. Liou, J.-J.; Rothrauff, B.B.; Alexander, P.G.; Tuan, R.S. Effect of platelet-rich plasma on chondrogenic differentiation of adiposeand bone marrow-derived mesenchymal stem cells. Tissue Eng. Part A 2018, 24, 1432-1443. [CrossRef] [PubMed]

14. Fice, M.P.; Miller, J.C.; Christian, R.; Hannon, C.P.; Smyth, N.; Murawski, C.D.; Cole, B.J.; Kennedy, J.G. The role of platelet-rich plasma in cartilage pathology: An updated systematic review of the basic science evidence. Arthrosc. J. Arthrosc. Relat. Surg. 2019, 35, 961-976.e3. [CrossRef]

15. Cooper, C.; Rannou, F.; Richette, P.; Bruyère, O.; Al-Daghri, N.; Altman, R.D.; Brandi, M.L.; Collaud Basset, S.; Herrero-Beaumont, G.; Migliore, A.; et al. Use of intraarticular hyaluronic acid in the management of knee osteoarthritis in clinical practice. Arthritis Care Res. 2017, 69, 1287-1296. [CrossRef] [PubMed]

16. Hermans, J.; Bierma-Zeinstra, S.M.A.; Bos, P.K.; Niesten, D.D.; Verhaar, J.A.N.; Reijman, M. The effectiveness of high molecular weight hyaluronic acid for knee osteoarthritis in patients in the working age: A randomised controlled trial. BMC Musculoskelet. Disord. 2019, 20, 196. [CrossRef]

17. He, W.-W.; Kuang, M.-J.; Zhao, J.; Sun, L.; Lu, B.; Wang, Y.; Jian-Xiong, M.; Ma, X.-L. Efficacy and safety of intraarticular hyaluronic acid and corticosteroid for knee osteoarthritis: A meta-analysis. Int. J. Surg. 2017, 39, 95-103. [CrossRef]

18. Dhillon, M.S.; Patel, S.; John, R. PRP in OA knee-Update, current confusions and future options. Sicot. J. 2017, 3, 27. [CrossRef]

19. Richards, M.M.; Maxwell, J.S.; Weng, L.; Mathew, G.; Golzarian, J. Inflammatories to products of regenerative medicine. Phys. Sportsmed. 2017, 44, 101-108. [CrossRef]

20. Baltzer, A.W.A.; Moser, C.; Jansen, S.A.; Krauspe, R. Autologous conditioned serum (orthokine) is an effective treatment for knee osteoarthritis. Osteoarthr. Cartil. 2009, 17, 152-160. [CrossRef]

21. Pishgahi, A.; Abolhasan, R.; Shakouri, S.K.; Zangbar, M.S.S.; Dareshiri, S.; Kiyakalayeh, S.R.; Khoeilar, A.; Zamani, M.; Khiavi, F.M.; Kheiraddin, B.P.; et al. Effect of dextrose prolotherapy, platelet rich plasma and autologous conditioned serum on knee osteoarthritis: A randomized clinical trial. Iran. J. Allergy Asthma Immunol. 2020, 19, 243-252. [CrossRef]

22. Jeyaraman, M.; Muthu, S.; Ganie, P.A. Does the source of mesenchymal stem cell have an effect in the management of osteoarthritis of the knee? Meta-analysis of randomized controlled trials. Cartilage 2020. [CrossRef]

23. Wang, A.T.; Feng, Y.; Jia, H.H.; Zhao, M.; Yu, H. Application of mesenchymal stem cell therapy for the treatment of osteoarthritis of the knee: A concise review. World J. Stem Cells 2019, 11, 222-235. [CrossRef]

24. Song, Y.; Du, H.; Dai, C.; Zhang, L.; Li, S.; Hunter, D.J.; Lu, L.; Bao, C. Human adipose-derived mesenchymal stem cells for osteoarthritis: A pilot study with long-term follow-up and repeated injections. Regen. Med. 2018, 295-307. [CrossRef] [PubMed]

25. Bansal, H.; Comella, K.; Leon, J.; Verma, P.; Agrawal, D.; Koka, P.; Ichim, T. Intra-articular injection in the knee of adipose derived stromal cells (stromal vascular fraction) and platelet rich plasma for osteoarthritis. J. Transl. Med. 2017, 15, 141. [CrossRef] [PubMed]

26. Centeno, C.; Pitts, J.; Al-Sayegh, H.; Freeman, M. Efficacy of autologous bone marrow concentrate for knee osteoarthritis with and without adipose graft. Biomed Res. Int. 2014, 2014. [CrossRef] [PubMed] 
27. Kim, J.-D.; Lee, G.W.; Jung, G.H.; Kim, C.K.; Kim, T.; Park, J.H.; Cha, S.S.; You, Y.-B. Clinical outcome of autologous bone marrow aspirates concentrate (BMAC) injection in degenerative arthritis of the knee. Eur. J. Orthop. Surg. Traumatol. 2014, 24, 1505-1511. [CrossRef]

28. Hede, K.; Christensen, B.B.; Jensen, J.; Foldager, C.B.; Lind, M. Combined bone marrow aspirate and platelet-rich plasma for cartilage repair: Two-year clinical results. Cartilage 2019. [CrossRef]

29. Zhao, X.; Zhao, Y.; Sun, X.; Xing, Y.; Wang, X.; Yang, Q. Immunomodulation of MSCs and MSC-derived extracellular vesicles in osteoarthritis. Front. Bioeng. Biotechnol. 2020, 8, 575057. [CrossRef]

30. Durant, T.J.S.; Dwyer, C.R.; McCarthy, M.B.R.; Cote, M.P.; Bradley, J.P.; Mazzocca, A.D. Protective nature of platelet-rich plasma against chondrocyte death when combined with corticosteroids or local anesthetics. Am. J. Sports Med. 2017, 45, 218-225. [CrossRef]

31. Krakowski, P.; Karpiński, R.; Jonak, J.; Maciejewski, R.; Jurkiewicz, A. Short-term Effects of arthroscopic microfracturation of knee chondral defects in osteoarthritis. Appl. Sci. 2020, 10, 8312. [CrossRef]

32. Lamo-Espinosa, J.M.; Mora, G.; Blanco, J.F.; Granero-Moltó, F.; Núñez-Córdoba, J.M.; López-Elío, S.; Andreu, E.; Sánchez-Guijo, F.; Aquerreta, J.D.; Bondía, J.M.; et al. Intra-articular injection of two different doses of autologous bone marrow mesenchymal stem cells versus hyaluronic acid in the treatment of knee osteoarthritis: Long-term follow up of a multicenter randomized controlled clinical trial (phase I/II). J. Transl. Med. 2018, 16, 1-5. [CrossRef]

33. Cole, B.; Karas, V.; Kristen, H. Hyaluronic acid versus platelet-rich plasma: A prospective, double-blind randomized controlled trial comparing clinical outcomes and effects on intra-articular biology for the treatment of knee osteoarthritis. Am. J. Sport. Med. 2017, 45, 339-346. [CrossRef] [PubMed]

34. Lamo-Espinosa, J.M.; Blanco, J.F.; Sánchez, M.; Moreno, V.; Granero-Moltó, F.; Sánchez-Guijo, F.; Crespo-Cullel, Í; Mora, G.; San Vicente, D.D.; Pompei-Fernández, O.; et al. Phase II multicenter randomized controlled clinical trial on the efficacy of intra-articular injection of autologous bone marrow mesenchymal stem cells with platelet rich plasma for the treatment of knee osteoarthritis. J. Transl. Med. 2020, 18, 1-9. [CrossRef]

35. Kellgren, J.H.; Lawrence, J.S. Radiological assessment of osteo-arthrosis. Ann. Rheumat. Dis. 1957, 16, 494-502. [CrossRef] [PubMed]

36. Kellgren, J.H.; Lawrence, J.S. Rheumatism in miners. II. X-ray study. Br. J. Ind. Med. 1952, 9, 197-207. [CrossRef]

37. Bellamy, N.; Campbell, J.; Robinson, V.; Gee, T.; Bourne, R.; Wells, G. Viscosupplementation for the treatment of osteoarthritis of the knee. Cochrane Database Syst. Rev. 2006, 2, CD005321. [CrossRef]

38. Yang, K.G.A.; Raijmakers, N.J.H.; van Arkel, E.R.A.; Caron, J.J.; Rijk, P.C.; Willems, W.J.; Zijl, J.A.C.; Verbout, A.J.; Dhert, W.J.A.; Saris, D.B.F. Autologous interleukin-1 receptor antagonist improves function and symptoms in osteoarthritis when compared to placebo in a prospective randomized controlled trial. Osteoarthr. Cartil. 2008, 16, 498-505. [CrossRef] [PubMed]

39. Lamo-Espinosa, J.M.; Mora, G.; Blanco, J.F.; Granero-Moltó, F.; Nuñez-Córdoba, J.M.; Sánchez-Echenique, C.; Bondía, J.M.; Aquerreta, J.D.; Andreu, E.J.; Ornilla, E.; et al. Intra-articular injection of two different doses of autologous bone marrow mesenchymal stem cells versus hyaluronic acid in the treatment of knee osteoarthritis: Multicenter randomized controlled clinical trial (phase I/II). J. Transl. Med. 2016, 14, 1-9. [CrossRef] [PubMed]

40. Gulotta, L.V.; Kovacevic, D.; Ehteshami, J.R.; Dagher, E.; Packer, J.D.; Rodeo, S.A. Application of bone marrow-derived mesenchymal stem cells in a rotator cuff repair model. Am. J. Sports Med. 2009, 37, 2126-2133. [CrossRef]

41. Kim, G.B.; Kim, J.D.; Choi, Y.; Choi, C.H.; Lee, G.W. Intra-articular bone marrow aspirate concentrate injection in patients with knee osteoarthritis. Appl. Sci. 2020, 10, 5945. [CrossRef]

42. Goyal, D.; Keyhani, S.; Lee, E.H.; Hui, J.H.P. Evidence-based status of microfracture technique: A systematic review of level I and II studies. Arthrosc. J. Arthrosc. Relat. Surg. 2013, 29, 1579-1588. [CrossRef] [PubMed]

43. Behery, O.A.; Harris, J.D.; Karnes, J.M.; Siston, R.A.; Flanigan, D.C. Factors influencing the outcome of autologous chondrocyte implantation: A systematic review. J. Knee Surg. 2013, 26, 203-211. [CrossRef] [PubMed]

44. Ganguly, P.; El-Jawhari, J.J.; Giannoudis, P.V.; Burska, A.N.; Ponchel, F.; Jones, E.A. Age-related changes in bone marrow mesenchymal stromal cells: A potential impact on osteoporosis and osteoarthritis development. Cell Transplant. 2017, 26, 1520-1529. [CrossRef] [PubMed]

45. Stolzing, A.; Jones, E.; McGonagle, D.; Scutt, A. Age-related changes in human bone marrow-derived mesenchymal stem cells: Consequences for cell therapies. Mech. Ageing Dev. 2008, 129, 163-173. [CrossRef]

46. Yang, Y.H.K. Aging of mesenchymal stem cells: Implication in regenerative medicine. Regen. Ther. 2018, 9, 120-122. [CrossRef] [PubMed]

47. Momaya, A.M.; McGee, A.S.; Dombrowsky, A.R.; Wild, A.J.; Faroqui, N.M.; Waldrop, R.P.; He, J.K.; Brabston, E.W.; Ponce, B.A. The cost variability of orthobiologics. Sports Health 2020, 12, 94-98. [CrossRef] [PubMed]

48. Wartolowska, K.A.; Gerry, S.; Feakins, B.G.; Collins, G.S.; Cook, J.; Judge, A.; Carr, A.J. A meta-analysis of temporal changes of response in the placebo arm of surgical randomized controlled trials: An update. Trials 2017, 18, 1-7. [CrossRef] 